\title{
Hane Halklarının Eğitim ve Kültür Harcamalarının Turizm Harcamalarına Etkisi
}

\author{
Sabriye Çelik Uğuz*
}

Balıkesir Üniversitesi, Burhaniye Uygulamalı Bilimler Yüksek Okulu, Balıkesir.

\section{$\ddot{O} z$}

Turizm talebini etkileyen toplumsal unsurlardan biri olan eğitim ve kültür seviyesi, seyahate olan ilgi ve merakı artırmakla birlikte bu ilgi ve merak kişilerin hem seyahat alışkanlığını hem de seyahat biçimini şekillendirmektedir. Ancak eğitim düzeyinin, kültürel bilinçlenmenin ve seyahate çıkma isteğinin artabilmesi için bu süreçte eğitim hizmetlerine ait harcamaların ve kültürel faaliyetler için yapılan harcamalarm da birlikte artırlması gerekmektedir. Bu nedenle çalışmada, Türkiye genelinde Türkiye İstatistik Kurumu (TUIKK)'nun 2015 Hanehalkı Bütçe Anketi (HBA)'ne ait yatay kesit veri seti kullanılarak eğitim-kültür harcamalarn ile turizm arasındaki ilişki ekonometrik olarak incelenmiştir. Elde edilen sonuçlara göre, turizm harcamalarmnn eğitim-kültür harcamalarn ve hane geliri ile pozitif; hane büyüklü̈̆̈̈ ile negatif ilişkili olduğu bulunmuştur.

Anahtar Kelimeler: Turizm Talebi, Eğitim ve Kültür Harcamaları, Yatay Kesit Modelleme

\section{The Effect of Education and Culture Expenditures of Households on the Tourism Expenditures}

\begin{abstract}
The level of education and culture, which is one of the social elements affecting tourism demand, both increase the interest and curiosity for travelling and also this interest and curiosity shape both travel habits and travel patterns of individuals. However, in order to increase the level of education, the cultural awareness and the desire to travel, it is necessary to increase the expenditures for educational services and cultural activities in this process. For this reason, the relationship between education-culture expenditures and tourism was examined economically by using the horizontal section data set of the Turkish Statistical Institute (TUIK) 2015 Household Budget Survey (HBS) for Turkey. Results show that tourism expenditures have positive effect on education-culture expenditures and household income while negative effect on the household size.
\end{abstract}

Keywords: Tourism Demand, Education and Culture Expenditures, Cross-Sectional Models

\section{GİRIŞ}

Birleşmiş Milletler Dünya Turizm Örgütü'nün (UNWTO) verilerine göre; turizm, ekonomik krizlere rağmen neredeyse kesintisiz bir büyüme gerçekleştirmiştir. Uluslararası turist varışlarının sayısı 1950 yılında 25 milyon iken 1980 yılında 278 milyona ve 2000 yılında 674 milyona ulaşmıştır. 2015 yılında ise, bir önceki yıla göre \%4,6 (52 milyon) artarak 1.186 milyona yükselmiştir. UNWTO'nun 2030'a Doğru Turizm adlı uzun vadeli tahmini raporunda 2010 ile 2030 yılları arasında uluslararası turist varışlarının yılda \%3,3 oranında artarak 2030 yılında 1.8 milyara ulaşacağ 1 ifade edilmektedir (UNWTO, 2016: 2-3). Turizm talebindeki bu hızlı büyümeden daha fazla pay almak ve turizmin ülkelerin kültürel ve ekonomik kalkınmasına sağladığ katkıdan faydalanmak amaciyla turizm talebini etkileyen unsurların analiz edilmesi önemli hale gelmektedir. 
Turizm literatüründeki önceki çalışmalarda turizm talebini etkileyen kültür ve eğitim dürtüsü, tatil alışkanlıklarında ve tatil sürecindeki ekonomik davranışlarda etkili olduğu kabul edilmiştir (Muller, 1991; Kotler, 2001; Alegre, Mateo ve Pou, 2009). Bu dürtüyü ortaya çıkaran eğitim ve kültür düzeyi, turizmin gelişmesini sağlamakla birlikte turizm talebini şekillendirmektedir. İyi eğitimli ve kültür seviyesi yüksek olan insanlarda değişik yerleri, farklı kültürleri tanıma isteği ve öğrenme eğilimi artmaktadır (İçöz, 2005: 143). Dolayısıyla bu istek ve eğilim turizme yönelik talebi de artırmaktadır. Aslında eğitim ve kültür hizmetlerinden faydalanmak bireylerin ortak bir ihtiyacı olmakla birlikte, toplumsal birliğin ve refahın en önemli yapıtaşlarından biri olarak kabul edilmektedir. Eğitim-kültür hizmetleri, bilgi ve iletişim teknolojileri sayesinde insanlar, ülkelerdeki doğal, tarihi ve kültürel miraslar hakkında daha fazla bilgi sahibi olmakta ve bunun sonucunda değişik kültürleri ve mekanları tanıma merakları artarak turistik çekiciliği olan bölgelere yönelme söz konusu olmaktadır (Richards, 1996: 272-273).

Eğitim düzeyi yükseldikçe buna paralel olarak hem meslek ve gelir düzeyi hem de kültürel donanım artmaktadır. Birbiri ile bağımlı olduğu kabul edilen bu unsurlar, karşılıklı olarak birbirini destekler ve geliştirir ve aynı zamanda turizme yönelik talebi de etkiler. Eğitim düzeyi yüksek ve buna bağlı olarak gelir düzeyi fazla, iyi bir meslek sahibi, kültürel olarak donanımlı kişilerin daha fazla seyahat alışkanlığına sahip olduğu bilinmektedir. Bu gerçekten yola çıkarak çalışmada, eğitim ve kültür düzeyi ile turizm arasındaki ilişki bir bütün olarak doğrusal boyutu ile ele alınmaktadır. Bireyin eğitim düzeyi yükseldikçe kültür düzeyi de artmakta ve buna paralel olarak seyahate yönelik ilgi, merak ve beklentiler de artmaktadır. Gerek örgün öğretim sürecinde gerekse bireylerin kültür faaliyetlerine katılımı ile birlikte kültürel değerler konusunda bilinç artmakta ve eğitim ve kültür düzeyi eş zamanlı olarak gelişmektedir.

Aynı zamanda kişilerin eğitim ve kültür düzeyi ile katıldı̆̆ı turizm çeşidi arasında da doğrudan bir ilişki mevcuttur. Genel anlamda eğlence-dinlence turizmi ile birlikte özellikle kültür, eğitim, sportif amaçlı turizme katılım çoğalmaktadır. Eğitim seviyesi yükseldikçe kültürel turizm etkinliklerine yönelik talep daha fazla artmakta (McKercher ve Du Cros, 2002: 185) ve kültür, destinasyon seçimini etkilemektedir (Richards, 2001: 7; Hughes ve Allen, 2005: 176). Artan kültür turizminin yanı sira bireylerin kişisel gelişimine ve kariyer olgusuna yönelik öğrenme amaçlı seyahatler de artmaya başlamıştır. Çünkü turizmin "bulunduğu ortamdan ve günlük yaşamdan kaçış" şeklindeki ana motivasyonu, "kendini geliştirme/zenginleştirme" şeklinde değişmeye başlamıştır (McCain ve Ray, 2003: 715). Kültür ve eğitim turizmi gibi alternatif turizm çeşitlerindeki bu gelişmelerle yeni bir turist tipi ortaya çıkmıştır. Bunlar, daha iyi eğitimli; daha kültürlü ve doğal çevre ile uyumlu; daha meraklı ve analitik; genellikle sadece dünyevi bilgileri değil, kişisel gelişimi sağlayacak bilgileri araştıran; turizme katılımda daha aktif kişilerdir (Ritchie, Carr ve Cooper, 2003: 26). Bu durum, bireylerin bilinçlendiğini göstermektedir.

Bu çalışmada, Türkiye'de bireylerin turizm hareketliliğine katılımı üzerinde etkili olduğu düşünülen eğitim ve kültür seviyesinin turizm harcamaları ile ilişkisi ele alınmıştır. Bireylerin kültür ve eğitim seviyesini temsil etmesi amacıyla kültür ve 
turizm harcama toplamı temsili değişken olarak kabul edilmiş ve hanehalklarının bu kültür-eğitim harcamaları ile turizm harcamaları arasında anlamlı bir ilişkinin varlığı araştırılmıştır. Literatürde, turizm faaliyetlerine katılım ile turistlerin kültür ve eğitim seviyeleri arasındaki ilişkiyi deneysel olarak ele alan ulusal ve uluslararası bir çalışmaya rastlanılmamıştır. Çalışma bu özgünlüğü ile ilgili literatürdeki önemli bir eksikliği dolduracaktır. Hanehalklarının turizm harcamaları; eğitim-kültür harcamalarının, hanehalkının gelirinin ve hane büyüklüğ̈̈nün bir fonksiyonu olarak ele alınmıştır.

\section{YÖNTEM VE BULGULAR}

Çalışmanın bu kısmında TÜİK tarafından yapılmakta olan HBA (2015) verilerinden yola çıkılarak, hanehalklarının kültür-eğitim ve turizm harcama eğilimleri incelenmiş ve turizm harcamalarını etkileyen faktörlerin analizine ve bu analizde kullanılan yöntem ve bulgulara yer verilmiştir.

\subsection{Veri Seti}

Söz konusu dönemde (2015) tabakalı iki aşamalı örnekleme yöntemi kullanılarak, her ay değişen 1272 hane olmak üzere yıl boyu 15264 örnek hanehalkına anket uygulanmış ve anketi geçerli kabul edilen 11491 haneye ait veriler derlenmiştir. 2015 yılında Türkiye genelinde hanehalkı başına aylık ortalama tüketim harcaması 3043 TL olarak tespit edilmiştir. Toplam harcamalar içinde en yüksek harcama payı \%26 oranı ile konut ve kira harcamaları ve \%20,2 ile gıda ve alkolsüz içecek harcamaları alırken, en düşük payı \%2 ile sağlık ve \%2,2 ile eğitim hizmetlerine ait harcamalar oluşturmaktadır. Lokanta ve otel harcamalarının payının \%6,4, eğlence ve kültür harcamalarının payı ise \%2,9 civarında gerçekleştiği görülmektedir (Tablo 1).

Tablo 1. Harcama Gruplarına Göre Toplam, Hanehalkı Başına ve Eşdeğer Fert Başına Ortalama Aylık Tüketim Harcamasının Dağılımı, Türkiye, 2014-2015

\begin{tabular}{|l|c|c|c|}
\hline Harcama türleri & Toplam & Hanehalkı & Eşdeğer ${ }^{(*)}$ fert \\
\hline
\end{tabular}




\begin{tabular}{|l|l|l|l|l|l|l|}
\hline & \multicolumn{2}{|c|}{$\begin{array}{c}\text { hanehalkı } \\
\text { tüketim } \\
\text { harcamasının } \\
\text { dağılıı }\end{array}$} & $\begin{array}{c}\text { başına aylık } \\
\text { ortalama } \\
\text { harcama }\end{array}$ & $\begin{array}{c}\text { başına aylık } \\
\text { ortalama } \\
\text { harcama }\end{array}$ \\
\cline { 2 - 7 } & 2014 & 2015 & 2014 & 2015 & 2014 & 2015 \\
\hline Toplam hanehalkı tüketim harcaması & 100,0 & 100,0 & 2848 & 3043 & 1351 & 1455 \\
\hline Gıda ve alkolsüz içecekler & 19,7 & 20,2 & 561 & 615 & 266 & 294 \\
\hline Alkollü içecekler, sigara ve tütün & 4,2 & 4,2 & 121 & 127 & 57 & 61 \\
\hline Giyim ve ayakkabı & 5,1 & 5,2 & 145 & 158 & 69 & 76 \\
\hline Konut ve kira & 24,8 & 26,0 & 705 & 792 & 335 & 379 \\
\hline Mobilya, ev aletleri ve ev bakım hizmetleri & 6,8 & 6,1 & 192 & 187 & 91 & 89 \\
\hline Sağlık & 2,1 & 2,0 & 60 & 61 & 29 & 29 \\
\hline Ulaştırma & 17,8 & 17,0 & 507 & 516 & 241 & 247 \\
\hline Haberleşme & 3,7 & 2,9 & 107 & 111 & 51 & 53 \\
\hline Eğlence ve kültür & 3,0 & 2,9 & 87 & 87 & 41 & 42 \\
\hline Eğitim hizmetleri & 2,4 & 2,2 & 68 & 66 & 32 & 32 \\
\hline Lokanta ve oteller & 6,0 & 6,4 & 172 & 193 & 82 & 92 \\
\hline Çeşitli mal ve hizmetler & 4,3 & 4,3 & 122 & 129 & 58 & 62 \\
\hline
\end{tabular}

Kaynak: TÜIK, Hanehalkı Bütçe Araştırması, 2015

* Düzeltilmiş OECD ölçeğine göre hesaplanmıştır.

Tablo 1'de görüldüğü üzere, hanehalklarının aylık ortalama harcaması hane başına eğlence ve kültür harcaması $87 \mathrm{TL}$, eğitim hizmetleri harcaması $66 \mathrm{TL}$, otel ve konaklama harcaması 193 TL'dir. OECD ölçeğine göre düzeltilmiş hane büyüklüğü endeksine göre ise, fert başına ortalama sırasıyla 42 TL, 32 TL ve 92 TL olarak tespit edilmiştir.

TUIK, Eğitim Harcama İstatistiklerine göre, Türkiye' de eğitim harcamaları 2015 yılında 2014 yılına göre \%12,2 artarak 135 milyar 22 milyon TL olurken, hanehalklarının yapmış olduğu eğitim harcaması 25 milyar 204 milyon TL gerçekleşmiştir (http://www.tuik.gov.tr/PreHaberBultenleri.do?id=21548). Kültür Ekonomisi istatistiklerine göre ise, kültür harcamaları 2015 yılında 2014 yılına göre \%6,5 artarak 32 milyar 941 milyon 728 bin TL ve hanehalkının 2015 yılındaki toplam kültürel harcaması 12 milyar 356 milyon 651 bin TL'dir (http://www.tuik.gov.tr/PreHaberBultenleri.do?id=21549).

\subsection{Yöntem ve Bulgular}

Çalışmada, öncelikle kültür-eğitim harcamaları ve turizm harcamaları arasında bir ilişki olup olmadığı korelasyon analizi ile incelenmiş ve Tablo 2'de sonuç gösterilmiştir.

Tablo 2. Korelasyon Analizi Sonuçları 


\begin{tabular}{|c|c|c|c|c|}
\hline \multicolumn{2}{|c|}{} & $\begin{array}{c}\text { Kültür-Eğitim } \\
\text { Harcamaları }\end{array}$ & $\begin{array}{c}\text { Hanehalkı } \\
\text { Geliri }\end{array}$ & $\begin{array}{c}\text { OECD } \\
\text { Hanehalkı } \\
\text { Büyüklü̆̆̈̈ }\end{array}$ \\
\hline \multirow{2}{*}{$\begin{array}{c}\text { Turizm } \\
\text { Harcamalar1 }\end{array}$} & Pearson Korelasyon & $0,374^{*}$ & $0,424^{*}$ & $-0,059^{*}$ \\
\cline { 2 - 5 } & Sig. (2-tailed) & 0,00001 & 0,00001 & 0,00001 \\
\cline { 2 - 5 } & $\mathrm{N}$ & 11489 & 11489 & 11489 \\
\hline
\end{tabular}

\%\%1 Seviyesinde istatistiksel olarak anlamlı

Tablo 2'de hanehalklarının toplam kültür-eğitim harcamaları ile pozitif ve istatistiksel olarak anlamlı bir korelasyon olduğu görülmektedir. Korelasyon analizi sonrası hanehalklarının turizm harcamalarının, kültür-eğitim harcamaları, hanehalkı yıllık kullanılabilir gelir ve OECD hanehalkı büyüklügünün bir fonksiyonu olarak ele alındığ1 model tahmin edilmiştir (Denklem 1). Hane büyüklügü değişkeni temsilen ilgili ankette yer alan "Yenilenmiş OECD Ölçeğine Göre Hane Büyüklüğü̈ değişkeni ile kullanılmıştır. Bu değişken, hanedeki ilk yetişkin için 1, 14 ve daha yukarı yaştaki fertler için 0.5, 14 yaşından küçük fertler için 0.3 değerleri dikkate alınarak hesaplanan hanehalkı büyüklüğüdür. Elde edilen katsayıları esneklik biçiminde yorumlayabilmek için çift logaritmik forma bir model tahmin edilmiş yani değişkenler logaritmik forma da kullanılmıştır.

$$
T H_{n}=\propto_{0}+\propto_{1} K E H_{n}+\propto_{2} H G_{n}+\propto_{3} H B_{n}+\varepsilon_{n} \mathrm{n}: 1 \ldots .11491
$$

Tablo 3. Model 1 Regresyon Analizi Sonuçları

\begin{tabular}{|c|c|c|}
\hline $\begin{array}{c}\text { Bağımlı Değişken } \\
\text { Turizm Harcamaları }\end{array}$ & Katsayı & Standart Hata \\
\hline Sabit & $-19,769^{*}$ & 0,571 \\
\hline Kültür-Ĕgitim Harcamaları & $0,177^{*}$ & 0,009 \\
\hline Hane Geliri & $4,415^{*}$ & 0,128 \\
\hline OECD Hane Büyüklüğü & $-2,599^{*}$ & 0,236 \\
\hline N:11489 & $\mathrm{R}^{2}: 0,417$ & $\mathrm{~F}: 806,725^{*}$ \\
\hline
\end{tabular}

*\%1 Seviyesinde istatistiksel olarak anlamlı

Elde edilen regresyon denkleminin açıklayıcılık gücü \%41,7 bulunmuştur (Tablo 3). Turizm harcama eğilimi gibi birçok unsur tarafından etkilenen bir değişken için tespit edilen açıklayıcılık gücü tatminkârdır. Giriş kısmında bahsedildiği üzere literatürde deneysel bir çalışma bulunmamasından dolayı kıyaslama olanağı yoktur. Üstelik, R $\mathrm{R}^{2}$ istatistiği ekonometri literatürü içerisinde çok önemli olmayan bir diagnostik'tir. Çünkü hesaplanış tekniği bakımından modele ilgili ve ilgisiz değişken ilave edildikçe yani modeldeki değişken sayısı arttıkça $\mathrm{R}^{2}$ istatistiği de artacaktır. Regresyon denkleminin bir bütün halinde anlamlılığını gösteren F-istatistiği değeri istatistiksel olarak anlamlıdır. 
Değişkenler için elde edilen sonuçlara bakıldığında ise, beklenildiği gibi kültüreğitim harcamaları, turizm harcamalarının istatistiksel olarak anlamlı bir fonksiyonudur. Kültür-eğitim harcamalarındaki \%1'lik artış turizm harcamalarını $\% 0,17$ artırmaktadır. Hanehalkı yıllık harcanabilir gelirinde meydana gelen \%1'lik artış ise turizm harcamalarını \%4,41 artırmaktadır. OECD hanehalkı fert büyüklügü değişkeni de istatistiksel olarak anlamlı ve beklenildiği yöndedir. Hanehalkı fert büyüklüğü arttıkça hanehalklarının turizm harcamaları azalmaktadır. Fert büyüklügünün \%1 artması turizm harcamalarını \%2,59 azaltmaktadır.

\section{SONUÇ VE ÖNERILLER}

Turizm talebinin belirlenmesinde psikolojik, toplumsal, ekonomik, çevresel vb. faktörler önemli bir rol oynamakta ve her bir unsur konu ile ilgili araştırmacılar tarafından ele alınmaktadır. Tüm faktörlerin etkisi olduğu kabul edilmekle birlikte artan eğitim ve kültür seviyesi ile turizm hareketliliğine yönelik talep çoğalmaktadır. Sanayileşme ve ardından küreselleşme sonucunda büyük bir ivme ile büyüyen turizm sektörü seyahati kolaylaştırırken, eğitim ve kültür seviyesinin artışına paralel olarak kişilerin merak etme ve dolayısıyla seyahat etme isteğini de artırmaktadır. Açıtır ki, kişilerin eğitim ve kültür seviyesinin artırması eğitim ve kültür hizmetlerine katılımla doğrudan ilişkilidir. Bu nedenle çalışmada temel amaç; kişilerin eğitim ve kültür seviyesinin belirleyici bir unsuru olarak eğitim-kültür harcamalarının turizme katılmada etkili olup olmadığını ortaya koymaktır. Turizm literatüründe teorik anlamda yaygın bir şekilde ortaya konulan eğitim ve kültür seviyesi ile turizm arasındaki ilişki, bu çalışmada ampirik olarak Türkiye içinde geçerli olduğu tespit edilmiştir.

Çalışmada elde edilen bulgulara göre; hanehalkına ait turizm harcamalarının kültür-eğitim harcamaları ile $\% 0,17$ düzeyinde ve hane geliri ile $\% 4,41$ düzeyinde anlamlı bir pozitif ilişki tespit edilmişken hane büyüklüğü ile \%2,59 düzeyinde negatif bir ilişki mevcuttur. Bu bulgulardan yola çıarak hanehalkının turizme katılımını arttıracak bazı öneriler şunlardır: Eğitim-kültür hizmetlerinden faydalanmak üzere bireylerin turizm bilinci oluşturulmalı ve bunun akabinde turizmin ülke içindeki gelişimi sağlanmalıdır. Yetersiz olan iç turizm talebini canlandırmak amacıyla yürütülen politikalarda eğitim ve kültür seviyesine uygun olarak alternatif turizm çeşitleri geliştirilmelidir.

Literatürde bu konu ile ilgili çalışmaların farklı eğitim ve kültür seviyelerinin ve de farklı disiplinlerin (mühendislik, sosyal bilimler vb.) turizm faaliyetlerine katılımının ayrı ayrı ele alınması, turizme katılımı artırmak yönündeki politikalara, potansiyel katılımcılar konusunda daha sağlıklı fikirler sunacaktır. Ayrıca çalışma bulguları teorik düzeydeki bir varsayımın geçerliliğini deneysel olarak da ispat etmesi bakımında kayda değerdir. Bir toplumda kültür ve eğitim seviyesinin artması, turizme bakış ve katılımda olumlu şekilde etkilemektedir.

Eğitimli, kültürel anlamda donanımlı ve bu doğrultuda mesleki açıdan iyi bir gelire sahip bireylerin turizme daha doğrusu lüks turizme yönelmesi beklenen bir sonuç olmasına rağmen kitle turizminin etkin olduğu yıllarda paket turlar sayesinde 
turizm farklı gelir gruplarına hizmet etmiştir. Çalışmada hane büyüklüğünün turizm harcamalarına olumsuz etkisini gidermek için ise, hanedeki fert sayısına göre paket turların çeşitlendirilerek turizme katılımın özendirilmesi gerekmektedir. Hanehalkının turizm bilinci oluşturularak iç turizm talebinin artırılması sağlanmalıdır.

\section{KAYNAKÇA}

Alegre, J., Mateo, S. ve Pou, L. (2009). Participation in Tourism Consumption and the Intensity of Participation: an Analysis of their Socio-Demographic and Economic Determinants, Tourism Economics, 15(3): 531-546.

Hughes, H. ve Allen, D. (2005). Cultural tourism in Central and Eastern Europe: the Views of Induced Image Formation Agents, Tourism Management, 26: 173-183.

İçöz, O. (2005). Turizm Ekonomisi. 3. Baskı, Ankara: Turhan Kitabevi.

Kotler, P. (2001). Marketing: an Introduction. (5th ed.). Upper Saddle River, NJ: Prentice-Hall.

McCain, G. ve Ray, N. M. (2003), Legacy Tourism: The Search For Personel Meaning In Heritage Travel, Tourism Management, 24: 713-717.

McKercher, B. ve Du Cros, H. (2002). Cultural Tourism, The Partnership Between Tourism and Cultural Heritage Management, New York: The Hawort Hospitality Press.

Muller, T. E. (1991). Using Personal Values to Define Segments in an International Tourism Market, International Marketing Review, 81: 57-70.

Richards, G. (1996). Production and Consumption of European Cultural Tourism, Annals of Tourism Research, 23(2): 261-283.

Richards, G. (2001), The Development of Cultural Tourism in Europe, İçinde; Cultural Attractions and European Tourism (Greg Richards: Editör), UK: CAB International, pp. 329.

Ritchie, B.W., Carr, N. ve Cooper, P. C. (2003). Managing Educational Tourism, 05 May1s 2017 tarihinde https://books.google.com.tr/books/about/Managing_Educational_Tourism.html?id=ptd XNo213D0C\&redir_esc=y adresinden erişildi.

TÜIK (2015), HBA Haber Bülteni, 15 Haziran 2017 tarihinde http://www.tuik.gov.tr/PreHaberBultenleri.do?id=21580 adresinden erişildi.

TÜIK (2015), Eğitim Harcama İstatistikleri, 15 Haziran 2017 tarihinde http://www.tuik.gov.tr/PreHaberBultenleri.do?id=21548 adresinden erişildi.

TÜİK (2015), Kültür Ekonomisi İstatistikleri, 15 Haziran 2017 tarihinde http://www.tuik.gov.tr/PreHaberBultenleri.do?id=21549 adresinden erişildi.

UNWTO (2016), Tourism Highlights, 2016 Editions, pp.1-16, 15 Mayı 2017 tarihinde http://www.e-unwto.org/doi/pdf/10.18111/9789284418145 adresinden erişildi. 